\title{
Down syndrome - a challenge for Latvian health care and education system
}

\author{
Julija Cirule-Galuza ${ }^{1,2,3,4, *}$, Ilze Strale ${ }^{1}$, Solvita Jegorenko ${ }^{1,2}$, Liga Priedena ${ }^{1}$, \\ Erika Gintere ${ }^{1,2,6}$, Aija Muceniece ${ }^{5}$, Ilze Durneva ${ }^{2,3,6}$, Sandris Cirulis ${ }^{3}$, and Liga Jansone ${ }^{3}$ \\ ${ }^{1}$ Liepaja Regional Hospital, Latvia \\ ${ }^{2}$ Liepaja Children Palliative Care Team, Latvia \\ ${ }^{3}$ NGO Dizhvanagi, Latvia \\ ${ }^{4}$ Rīga Stradinš̌ University, Latvia \\ ${ }^{5}$ CSCC "Kurzeme" branch "Liepaja", Latvia \\ ${ }^{6}$ Liepaja University, Latvia
}

\begin{abstract}
Down syndrome (DS) is a genetic disorder. From 1997 to 2015, 473 DS patients were born in Latvia. Prenatal diagnosis allows terminating pregnancies with high risk of DS. The aim of our research was to assess the impact of environmental quality (family and extrafamilial care) on the child's development, range of services for DS patients, and to identify the optimal early support system. Families and specialists were interviewed to analyze differences between children in families and institutional care clients. State financial support for a DS child in the family is less than to a child in institutional care, and does not provide adequate rehabilitation services. Conclusion: the environment (family/institution, available resources, and rehabilitation services) where the child grows up after the birth, determines both their quality of life and level of independence development. If the somatic problem-solving path is clear, then social integration needs to be improved. Support of inter-professional teams for the families is necessary immediately after the diagnostic statement in order to ensure a more favourable family environment and to reduce the risk of institutionalization. Despite the potentially higher early intensive rehabilitation costs, in the course of time we can predict that it will provide an economic effect on the state and improve the patient and their family's quality of life.
\end{abstract}

Key words: down syndrome, educational support, early intervention.

\section{Introduction}

Down syndrome (DS) is a multisystem disorder and is characterized by a significant cognitive disability. The triplication of specific genes on human chromosome 21 plays a big role in cognitive dysfunction in DS. The gene analysis identified over 1,300 genes that were disrupted at some point in the development of individuals with DS. They found $95 \%$ of these genes were in regions of the genome other than chromosome 21 . In the case of extra- $21^{\text {st }}$ chromosome genes, changes are connected with regulative issues, which are changed because of extra- $21^{\text {st }}$ chromosome. $21^{\text {st }}$ chromosome is the smallest of all human chromosomes and holds about $1.5-2 \%$ of all genetic information. In 2000 it was proclaimed

\footnotetext{
* Corresponding author: julijacirule@yahoo.com
} 
that all sequence of chromosome has been discovered. It was the second human genome's chromosome, which was fully sequestered. It holds 200-300 genes coding different protein synthesis.

DS was first described by an English physician John Langdon Down in 1862. He called it "mongoloid idiocy". Historically, many individuals with DS were killed, abandoned or ostracized from the society. In the $20^{\text {th }}$ century, it was common for these individuals to be institutionalized, and they did not receive appropriate treatment for the associated medical complications. Many children with DS therefore used to die during infancy or early adulthood. Since 1960 there were articles against the term of "mongoloid idiocy". So, the term of "Down syndrome" was accepted. In 1965 this term was accepted by WHO and became the official name for this pathology. The genetic basis of the disease was discovered by Dr. Jerome Lejeune in 1958, that is why it is also possible to call it as "Lejeune syndrome".

Taking into account that this syndrome is quite common and studied, it was decided to understand what is happening with children with DS in Latvia. In spite of the various myths that are connected with it, there is a gradual increase in the belief that, from all possible genetic problems, DS is a relatively "successful lot". Now, also in Latvia, we can see DS patients in the society more often and we have to think of strategies improving their integration into independent life.

\section{Description of research}

Aim of the research: research the situation with health issues and cognitive development in children with DS in Latvia in relation with their social environment.

Tasks of the research:

1 Develop a questionnaire and analyze information on possible differences in children with Down syndrome growing in a family and children in the Care Centre in relation to the cognitive development and state of health.

2 Investigate the national financial involvement and support in upbringing a child with DS depending on the social environment.

3 Investigate the problems, which are topical to the parents bringing up DS children and make recommendations.

Research object: Cognitive development and self-care abilities in children with DS living in Latvia.

Research methods: The research used a general theoretic descriptive method for analyzing international literature on the topic, the method of data collection - questionnaire, and the subsequent mathematical-statistical analysis of data and interviews. The study is combined quantitative and qualitative. The questionnaires were designed for families with DS children and for specialists of an institution, SSCC "Kurzeme" branch "Liepaja", where some of clients with DS live. Parents and specialists received questionnaires and answered questions independently about every child. After receiving of questionnaire, authors asked respondents about their expectations from children in future and were asked to name the biggest problems in relation with a potential future of children, and their fears about future, as well as about feelings soon after parents discovered that their child have trisomy 21 . The questionnaire consists of demographic data that does not show the identity of a child (gender and age only), questions that focus on parents' social situation, memories of pregnancy and first contact with information that the baby is expected to have or already has been born with Down syndrome. The next set of questions focused on the medical problems that the child encountered during their growth; social characteristics of the family, difficulties of acquiring the child's education, process of cognitive development of the child, parents' plans and expectations regarding the 
child was the topic of the third part of the questionnaire. Additionally, parents were given the possibility to answer questions about state financial support because a child with special needs grows in the family. Parents had also a space for free style comments about their topical problems with the child and life with the child. The questionnaire was also modified for the use in a social care institution where children with special needs, including children with Down syndrome, live. Social workers and caregivers were also surveyed. We also performed telephone interviews with specialists working in the field, to discover information about actual legal and financial support from the state as well as available social services in different districts. We also analyzed data collected by the National Statistics Office.

\section{Results}

\subsection{Summary of scientific information}

There has been much more research of DS in the last decade; it can be related to the fact, that DS has several similarities with Alzheimer's disease (AD). The number of AD cases has increased during the recent years, and DS patients are the clear risk group for it - so, researchers try to find out the pathologic physiology and common factors for both pathologies, and it could help in future to achieve better cognitive and health outcomes in DS patients. Both groups (DS and AD patients) have similar looking brain with higher levels of the protein beta amyloid [9, 299-230]. In fact, patients with DS develop the abnormal protein at twice the rate. Results of a pilot study [10, 239], confirm the pathogenic role of beta amyloid in dementia as seen in both AD and DS. The changes in hippocampus also were proven. The latest study shows that dysfunction at the input synapses of the hippocampus propagates around hippocampal circuits in the mouse model of DS, resulting in unstable information processing by place cells and impaired learning and memory. Even subtle impairments of this type will profoundly influence intellectual abilities.

DS is also connected with the defective stem cell regulation throughout the body (Stanford University School of Medicine, Sept. 11, 2013). The defects in stem cell growth and selfrenewal, observed by researchers, can be alleviated by reducing the expression of just one gene, Usp16, on chromosome 21 . The finding raises the possibility of an eventual therapy based on reducing its expression. Reducing Usp16 expression in skin and nerve-progenitor cells from people with DS allowed the cells, which usually proliferate slowly, to assume normal growth patterns.

From the World Statistics we can see that this condition affects individuals of all ethnicities. It occurs in about one per 700 babies in the United States, and 6 million worldwide (1:800 births). As the life expectancy for people with DS has increased in recent years - from 25 in 1983 to 60 today - the research aimed to understand the cause of conditions that affect their quality of life are essential. During the last 18 years 431 patients with DS were born in Latvia (1998-2015) (Table 1).

As we can see, up to 2013 statistics in Latvia is close to the world statistics, but in 2013 when the Regulations of the Cabinet of Ministers defined stronger qualification for specialists and equipment for risk pregnancy testing, our statistics indices improved, and the incidence now is even higher than in highly developed countries - 1 per 1100 birth. It also indirectly shows that people are not feeling safe if they expect a child with a genetic pathology, and mostly decide to terminate pregnancy if the possibility for DS is high enough.

The changes, typical for DS, can be determined from the $9^{\text {th }} / 10^{\text {th }}$ week of pregnancy. Sophisticated diagnostic methods are available for the second trimester of pregnancy. In the world, $92 \%$ of women who receive positive screening results terminate their pregnancy. $96 \%$ of women, who give birth to DS children, do not raise them (data 
Table 1. Children born with Down syndrome in Latvia every year [12].

\begin{tabular}{|c|c|c|c|c|c|}
\hline Year & $\begin{array}{c}\text { Children } \\
\text { were born }\end{array}$ & $\begin{array}{c}\text { Children with DS) } \\
\text { (abs.No./to 1000 born) }\end{array}$ & Year & $\begin{array}{c}\text { Children } \\
\text { were born }\end{array}$ & $\begin{array}{c}\text { Children with) } \\
\text { (abs.No./to 1000 born) }\end{array}$ \\
\hline 1998 & 18410 & $29($ apx 1: 635) & 2007 & 23958 & 22(apx 1: 1009) \\
\hline 1999 & 19396 & $37($ apx 1: 525) & 2008 & 24397 & $32(\operatorname{apx} 1: 762)$ \\
\hline 2000 & 20302 & $26(\operatorname{apx} 1: 780)$ & 2009 & 22044 & $16(\operatorname{apx} 1: 1378)$ \\
\hline 2001 & 19726 & $42(\operatorname{apx} 1: 470)$ & 2010 & 19781 & $14(\operatorname{apx} 1: 1420)$ \\
\hline 2002 & 20127 & $20(\operatorname{apx} 1: 1006)$ & 2011 & 18825 & $18(\operatorname{apx} 1: 1046)$ \\
\hline 2003 & 21151 & $32(\operatorname{apx} 1: 661)$ & 2012 & 19897 & $32(\operatorname{apx} 1: 622)$ \\
\hline 2004 & 20551 & $27(\operatorname{apx} 1: 760)$ & 2013 & 20596 & $16(\operatorname{apx} 1: 1287)$ \\
\hline 2005 & 21879 & $21(\operatorname{apx} 1: 1040)$ & 2014 & 21746 & $13(\operatorname{apx} 1: 1673)$ \\
\hline 2006 & 22871 & $24(\operatorname{apx} 1: 953)$ & 2015 & 21979 & $11(\operatorname{apx} 1: 2000)$ \\
\hline
\end{tabular}

from http://panoramatest.ru/sindrom-dauna/). Latvian obstetric specialists in an interview agreed that in almost every case with prenatal DS positive signs, pregnancy is terminated. Some of DS children's mothers in their questionnaires noticed that they intentionally did not undergo diagnostics, because of the disagreement with pregnancy termination in any case.

Typical problems for patients with DS are: hypotonia; eye symptoms (N.abducens nuclear aplasy, N.abducens aplasy, different problems with eye muscles innervation, accommodation problems) and a flat nasal bridge; a single crease across the palm known as the palmar crease; low birth weight; delayed ability to crawl and walk (they usually can run at the age of 26 months, but movements are often clumsy because of hypotony, and they usually cannot run the same distance with the same speed as their peers), some degree of learning disability; speech delay - first words since $24 \mathrm{~m} / \mathrm{o}$, 2-word sentences since $36 \mathrm{~m} / \mathrm{o}$ [11, 135-137]. The level of learning disability also varies between individuals, with some only experiencing mild intellectual disability (IQ 50 to 70) and others experiencing severe difficulties (IQ 20 to 35). The measuring of IQ in these kids is quite inaccurate and there are groups who work to improve the possibilities of testing. Parents in Latvia, who wrote to us letters after questionnaire fulfilling, also wrote that this testing is a big problem, because the testing environment and also tests that children have to go through, do not show the typical reactions and abilities of a child, but his ability to show their skills in a stressful situation.

Medical conditions, connected with DS, are quite diverse. One of potentially fatal conditions can be a congenital heart disease. Nearly half of DS sufferers are born with a heart defect, requiring hospitalization and treatment in about $60 \%$ of cases, most commonly - a septal defect. An interesting fact is, that foetus with DS usually has hypercholesterolemia during intrauterine life [5, 540-543] - that could also be one of the factors connected with defects in cardiovascular system. Another very severe condition is blood pathology. Leukemia is significantly more common among children suffering from DS. The higher risk is for acute lymphocytic leukemia, acute myeloid leukemia and transient leukemia, a condition similar to leukemia that arises in the first month of life but resolves independently of treatment. People with DS are also at an increased risk of either hypo or hyperthyroidism. Sometimes it is connected with a supplemental deficit of $\mathrm{Zn}$, and $\mathrm{Zn}$ level correction can help to improve the condition [6, 257-268].

Only around $30 \%$ to $50 \%$ of females with DS are estimated to be fertile and the menopause usually occurs at an earlier age than in the general population. Males with the condition do not usually father children, although it is unclear whether the cause is poor sperm development or lack of sexual activity. But it is possible to find case reports about healthy children born in family with a father with DS [7, 675]. 
Individuals with DS experience intestinal problems, such as constipation, indigestion, diarrhoea and obstruction of the bowel. Around 5\% to $15 \%$ of people with DS develop celiac disease. Some children may be born with imperforate anus (the absence of an anal opening) or Hirschsprung's disease. A number of studies describe food intolerance and malabsorption. If an early period of life is connected with feeding difficulties, then later adolescent time is often connected with obesity. DS people with overweight or obesity are linked with a slow metabolic rate, abnormal blood leptin concentrations and exhibit low levels of physical activity. It can be partially connected with lower expending of calories and decreased resting metabolic rate among person with DS [3, 858-861, 4, 264-266]. Vitamin B group deficiencies and abnormal blood homocysteine levels decrease the rate of intellectual development in DS cases - so intestinal problems relate to intellectual, and it shows a huge role of good diet for children with DS [8, 228-235]. Early dietary interventions by parents or guardians of DS children provide an opportunity for decreasing the risk or delaying some of the DS associated conditions from appearing, thus affecting beneficially their quality of life [1, 1310-1318, 2, 1382-1387]. Nearly 50\% of DS patients have visual disturbances such as a disturbed convergence or accommodation, cataract, keratoconus or nystagmus. Sometimes vision problems can explain low reading skills in patients.

Additionally, it is important to be alert for signs of abuse and neglect [13, 57-69] - as well in the family, school or institution, especially with a non-verbal adolescent. In the open question, parents of adolescent patients with DS wrote about cases when their children suffered from physical abuse from their peers in the street, when they were walking independently around or on their way to school. Therefore, most of parents do not allow their children to travel alone despite the fact that child's abilities allow them to do it. Children who grow up in a Social Care institution do not have a possibility to be outside their home or school without their tutors, so they cannot prove their ability to be independent. We did not find also any rehabilitation centres where children with DS can undergo rehabilitation services without their caregivers.

Despite the fact that DS patients benefit a lot from life in a family and developing environment, a lot of patients have to grow up in institutions. Regardless of worldwide success stories of DS patients who can receive good education, run their business and have their own family life, we could not find any family in Latvia, who is safe about their child's future, because changes in the educational system are very slow and do not prepare DS patients to an independent professional life. In the questionnaire, one of the points we wanted to clarify was the age at what the child came to the institution - and what was the reason for it. From our small group of institutionalized children we could see that the average age of coming to the institution was 4 , and the reason the parents mention most often was the problem of caring for the child during the time when the parents have to work, and the lack of a possibility to provide the child with rehabilitation. Most of the parents, who bring up children with DS in their families, wrote to us, that the biggest problem for them is the unknown future - they understand that there is no system in Latvia to help their children to be trained for simple work or independency; they do not feel safe about their child's future. The only mother, who responded that she was safe about her child future, was an adoptive mother, who adopted the child with DS from Latvia and lives in the USA.

\subsection{State financial support for DS child's life}

As to financial aspects of raising the child with DS, it is necessary to divide it in two parts children in the family and in institutional care. If a child lives in an institution, the state spends 600-2000 euro per month for the child, 600 euro per month if the child lives in a children home, 300 euro if the child attends a boarding school (most of the children with 
DS in an institution attend such schools) and 1080 euro per month if the child is placed into hospital. Thus if the child lives in a children home and attends a boarding school, and spends a month in a psychiatry unit of a hospital - the state would spend 1980 euro to cover all expenses. Ombudsman research in Latvia in 2015 has shown that the frequency of hospital stay for children from an institution is much higher than for the children living in families. Speaking about financial support for families, it contains different parts: the state financial support for a child with disability 106.72 euro. An additional support, if the child needs a special care (just in some cases) 213.43 euro - most of DS small children families have this benefit. Transport benefit 79.68 euro for 6 months - if there are mobility problems. The family benefit ( 11.38 euro for the $1^{\text {st }}$ child, 22.76 for the $2^{\text {nd }}$ child, 34.14 for the third and the next). If a gastroenterologist finds a celiac disease -106.72 euro per month additionally. Two examples:

1. A Child with DS living with a guardian (Ieva, a 10-year-old girl) $-606.59+79.68 /$ half of a year for transport, from this money -216 euro come from the girl's parents (Guarantee's Fund) + the assistant fee 59 euro per month.

2. A child with DS who lives with a single mother and has proven celiac disease (Annemarie, 16 years old) $-331.50+$ the assistance fee.

So, actually, we can see that in most of the cases the state has to spend more money if the child grows up in an institution. On the other hand, if the child, living in the family, has a chance to more or less independent life as an adult, with a support of their family - then the children, who spend their life in an institution, usually do not have the family support and stay in the institution lifelong.

Parents in the answers to the open question wrote that the state financial support for families with DS children is not enough to cover the needs for rehabilitation. At present, we do not have any effective mechanisms to provide an early intervention and intensive rehabilitation work with children who live in families. Parents' education as well in insufficient - all initiative comes from parents, and they have to be very motivated to find out how to help their child better. Thus at the time when the child's mother has to return to work, her child mostly receives only a restricted amount of rehabilitation or falls out of the rehabilitation system. The WHO data also shows a tendency that family with a disabled child is the risk group for poverty - and in most of the cases, it is the main reason to place the child into an institution.

\subsection{Analysis of the questionnaires}

We analyzed 26 questionnaires (14 - families with a DS child, 12 - children who live in an institution, the age is 1-21, all questionnaires were filled by either parents of children with DS or specialists of institutions). Much more questionnaires were sent, but a big part of parents are tired of participation in researches and do not believe that it can help the situation - so they choose not to answer questions at all, or agreed only to speak about their expectations and fears in informal conversation, but did not answer questions in questionnaires. It was interesting to see that there were $62 \%$ boys and $38 \%$ girls in an institution, $56 \%$ girls and $44 \%$ boys in families. This may indirectly indicate that more often the family sees the boy as a follower of the family, and therefore it is easier to accept and "tolerate" the girl with chromosomal trisomy 21, rather than the boy. From children, who live in families, just in one case parents were informed about DS in the child and did not terminate pregnancy for others the syndrome was not noticed during pregnancy. Of the children in social care centre $62 \%$ came to the institution immediately after the birth (as it was written in the 
documents - because of health issues, actually - mostly because parents were not ready to raise the child with disability and did not feel safe about their future. These parents also never visited their child in the institution, which shows mostly the parents' psychological problems with denial of the birth of a "non-standard" child), 38\% - later (approximate age - 4). We can see that most of the parents chose to terminate pregnancy after prenatal diagnosis, but, if they chose not to do it, they were ready to fight for the child's future. Parents, who participated in this research, noticed, that they needed an early support as family in crisis - especially immediately after the birth and during the child's first year of life - they had support only from relatives or social networks, but not from professionals. We can see that life in loving and supportive family, especially during the first 3 years of life, is critical for the child's cognitive and motor development. An early support and intervention is working successfully in the USA.

As to the health condition, we did not see any proofs that children, who are placed into an institution, have more of co-morbidities or have more severe health conditions after the birth. Despite the fact that children in both groups have a cognitive deficit (100\% - of children in an institution, close to $80 \%$ - children in families), more often children in families had combined health problems - we had also one respondent, whose DS child had almost all possible types of pathologies. Of course, children with DS had different pathologies, as we have shown in Table 2, but it seems that a more complicated pathology after the birth gives parents the possibility to have a multidisciplinary support, so they can deal with crisis of a new situation in the family more easily, and continue to raise the child in the family. Interesting, that none of all the children in social centre had congenital heart problems - and cardiac surgery usually means that the family will have regular supervisions during at least one, more often first five years of the child's life. Moreover, parents show their children to specialists more often, so children have many more labels of co-diagnosis compared to children in an institution who do not have that "autistic spectrum disorder" or "hypotony" as a set diagnosis - because the staff, who work with them, accept it as a part of the syndrome. Parents also noticed that children with DS often have periods with sleep problems. Sleeping problems are also investigated in DS children, because this symptom is very disturbing for the whole family $(14,197-204)$. Not all children with DS recognized having sleep problems or atopy, or food allergy. That could be related with a strict regime of daily routine and diet - so they just do not develop these complications. Therefore one piece of advice for DS children's parents could be to make a strict healthy diet and daily routine to help the child become healthier.

Answering about serious co-morbidities in DS patients, University hospital specialists could find statistical data on the last 15 years (Centre of Children Haematooncology). At that time there were 7 cases with oncohaematologic conditions in DS children in Latvia (AML - 2, ALL -4 , transitor mielopathy - 1). 3 from these children died, 1 continues to receive palliative care with $2^{\text {nd }}$ ALL recidive, 3 have remission - so, mortality in these cases was $57 \%$.

As to the cognitive development, children in families show much better results, as institutional residents (Tables 3, 4).

At the same time, the difference in later age is not so big, and most of DS children from families did not achieve the level of easy reading and writing. Comparing the rehabilitation work with the children in families and in an institution, we can see that children in an institution have a professional support at minimal level during all their time in the institution. At the same time, children from families had more intensive work during the first 7 years of life (when the Portridge System and two rehabilitation courses per year are available). The intensity of rehabilitation after school age achievement drops dramatically, so we can see, that more intensive specialist's support during the first years of life gives real results, but it is necessary to continue the work during the whole childhood period. 
Table 2. Co-morbidities in DS patients who live in families and in Social Care Center.

\begin{tabular}{|l|c|c|}
\hline Statement & Care Center & Families \\
\hline Mental retardation & $100 \%$ & $72 \%$ \\
\hline Speech retardation & $100 \%$ & $79 \%$ \\
\hline Thyroid problems & $25 \%$ & $35 \%$ \\
\hline Congenital heart problem & - & $49 \%$ \\
\hline Food allergies & $12.50 \%$ & $21 \%$ \\
\hline Celiac disease & $12.50 \%$ & $21 \%$ \\
\hline Atopy & $12.50 \%$ & $21 \%$ \\
\hline Bronchial asthma & $12.50 \%$ & $0 \%$ \\
\hline Muscular hypotony & - & $93 \%$ \\
\hline Diabetus mellitus I & - & $14 \%$ \\
\hline Septic endocarditis & - & $7 \%$ \\
\hline Autistic spectrum problems & - & $28 \%$ \\
\hline Haemotooncology & - & $14 \%$ \\
\hline Vision problems & $100 \%$ & $100 \%$ \\
\hline
\end{tabular}

Table 3. Reading skills in DS children.

\begin{tabular}{|l|c|c|}
\hline Statement & Care Center & Family \\
\hline Child cannot read & $88 \%$ & $42 \%$ \\
\hline Child recognizes some letters & $50 \%$ & $14 \%$ \\
\hline Child recognizes all letters & - & $21 \%$ \\
\hline Child can read words & - & $21 \%$ \\
\hline
\end{tabular}

Table 4. Writing skills in DS children.

\begin{tabular}{|l|c|c|}
\hline Statement & Care Center & Family \\
\hline Draws circles and lines & $100 \%$ & $56 \%$ \\
\hline Draws pictures, but cannot write & $25 \%$ & $21 \%$ \\
\hline Writes some letters and numbers & $25 \%$ & $28 \%$ \\
\hline Can write some familiar words & $38 \%$ & $7 \%$ \\
\hline Can write words without help & - & $14 \%$ \\
\hline Can rewrite the text & - & $14 \%$ \\
\hline Can write little sentences without help & - & $7 \%$ \\
\hline
\end{tabular}

Table 5. Independency level.

\begin{tabular}{|l|c|c|}
\hline Statement & Care center & Family \\
\hline Able to dress & $88 \%$ & $70 \%$ \\
\hline Toilet trained & $76 \%$ & $63 \%$ \\
\hline Eats independently & $100 \%$ & $63 \%$ \\
\hline Able to cook & $50 \%$ & $35 \%$ \\
\hline Knows how to tidy up the room, able to assist in the farm work & $50 \%$ & $56 \%$ \\
\hline Able to use public transport independently & - & $14 \%$ \\
\hline
\end{tabular}

The independence level in institutional children was higher for younger children, but in later period of life family children show better results (Table 5).

Of course, the medium age in both groups differs, so it is hard to get clear results from only this table. Such abilities as dressing and eating develop quicker in an institution the staff members are highly motivated to develop these functions in children because they 
do not have extra caregivers to assist every children every time with these functions. But in every case, children with DS can get these skills earlier or later, but the independent life skills (household work, traffic use) are higher in families. Analysis of children's functional development shows that it is necessary to improve parent/caregiver skills in couching and training the kids to be more independent and to use their abilities in real life situations.

\section{Discussion}

We can see that institutional care for children with disability is much more expensive for the state, compared to the cases when a child is raised in a family. This is also proved by numerous studies that have been carried out in recent times not only in medicine, but also in the social field $(15,5-10,16,6-16)$. The results, if we analyze the cognitive abilities, are much better in families, too. However, even for children who live in a family we can see the problem with an appropriate professional training and life skill education is good enough to start their own life after it. Why do the results of our children with DS differ? Is it the question of a low motivation - in parents, in educators, social care specialists - or are there some objective reasons? One aspect is the low intensity of work with the family and child, especially in the early period of life. As researches show, family outcomes among parents of DS children, who receive early intervention, is more than 60 percent better, compared to parents of DS children who receive late intervention (but also in the cases with late intervention children were better than without it in $40 \%$ of cases) (17, 998-1001). The positive impact for family from the early intervention is also seen in researches, and it is the process that we need to establish in Latvia as well. There is a significant link between the acceptance level of intervention, parents' education level, family's income and the family outcomes. Parents of children who receive early intervention were more positive in understanding the strengths, abilities and special needs of their children compared to other family outcomes. Our system needs active parents, who are ready to look after, help and to continue specialists' work at home, provide the child with a developing environment and motivation. Thus, the goals for these children are not often high enough, so they also do not have an adequate support and rehabilitation to achieve more. The main needs for children and their families are functional training, independence training (ability to make a decision and to ask for help if needed), strategies training for compensation of weaker skills, and some supportive moments in inclusive education. Unfortunately, we cannot often provide all of them to DS patients. Parents have to invest a lot in the child's development, providing them everyday training on a regular basis and becoming "the child's specialist" - if they want to see good results. It shows the necessity of an early multidisciplinary team support for every family after the childbirth if they have a DS child. DS children must grow in the family - not in an institution. Early intervention could not only support and educate parents and help them to be the child's specialist, but also can notice risk situations and avoid neglect and abuse cases in families, and diminish the risk of institutionalization. It is important to notice timely the co-morbidities and help children to improve. For example, these children can benefit from autism screening on a routine basis. In the research, among DS children weighted prevalence of autistic disorder and total ASD were $6.4 \%$ in screeningnegative and $18.2 \%$ in screening-positive children. Screening test sensitivity was $87.5 \%$; specificity was $49.9 \%(18,185-191)$. The prevalence is substantially higher than in general population. There is a need for deeper research of development of specific ASD screening algorithms and improved diagnostic discrimination in children with DS. Timely identification of these co-occurring diagnoses is essential, so that appropriate interventions can be provided. 


\section{Conclusions}

1. Children with DS can have higher cognitive development in families, but they need more independency to fulfil self-care skills. It is also necessary to follow the skills and cognitive development on regular basis, as well as the speed of development. Early intervention can help to see and understand the problem (so it is the interdisciplinary work with a possibility to involve other specialists if necessary), it involves case coordinators, who know all information about the child and can provide support to the family. For better outcomes for DS patients, we need to organize such early intervention and support system for parents of DS children in Latvia.

2. Support in a very early life period will diminish the risk of institutionalization and give better outcome for DS patients. Better cognitive results in every child will give better outcomes for all community. State financial support for families with DS children could be connected with the possibility for rehabilitation; it can give a great stimulation in rehabilitation services use, and will help the child to get skills, necessary in independent life. For now, support is not enough to cover the long-term needs for rehabilitation. The state spends more money on the child raising them in an institution instead of supporting rehabilitation for children living in families.

3. The main problem for parents of children with DS is to organize environment, what can help the child to improve cognitive skills and to prepare him to independent life in future. Environment is very important - the situation of social isolation for the child and family is extremely risky. Possible way of resolving of it includes the organization of age-appropriate activities, inclusive education with the specialist's support, integration of education on everyday basis and everyday situations, as well as physical training, healthy food and healthy environment from early age.

4. There is a need for more research of the ways to improve DS patient's social integration, and also real work to achieve this goal.

\section{References}

[1] A.M. AbdAllah, S. Raffa, T. Alaidaroos, R. Obaid, J. Abuznada, Life Sci. J. 10(3), 1310-1318 (2013)

[2] T. Adelekan, S. Magge, J. Shults. Pediatr. J. 129(6), 1382-1387 (2012)

[3] D.B. Allison, J.E. Gomez, S. Heshka , R.L. Babbitt, A. Geliebter, K. Kreibich, S.B. Heymsfield, Int. J. Obes. Relat. Metab. Disord. 19, 858-861 (1995)

[4] J. Bauer, U. Teufel, C. Doege, G. Hans-Jeurgen, B. Beedgen, O. Linderkamp, Pediatr. J. 143, 264-266 (2003)

[5] L. Bocconi, S. Nava, R. Fogliani, U. Nicolini. Am. J. Obst. Gynecol. 176(3), 540-543 (1997)

[6] I. Bucci, G. Napolitano, Biol. Trace. Elem. Res. 67, 257-268 (1999)

[7] J. Assist. Reprod. Genet. 2016 May; 33(5): 675. doi: 10.1007/s10815-016-0688-2. Epub 2016 Mar 14

[8] K. Chad, A. Jobbing, H. Frail, Am. J. Ment. Retard. 95, 228-235 (1990)

[9] X. Wang, T. Huang, Y. Zhao, Q. Zheng, R.C. Thompson, G. Bu, Y. Zhang, W. Hong, H. $\mathrm{Xu}$, Original Research: Full open access research for "Sorting Nexin 27 Regulates A $\beta$ Production through Modulating $\gamma$-Secretase Activity" by in Cell Reports. Published online October 23, 2014 doi: 10.1016/j.celrep.2014.09.037

[10] M.S. Rafii, H. Wishnek, J.B. Brewer, M.C. Donohue, S. Ness, W.C. Mobley, P.S. Aisen, R.A. Rissman. Original Research: Full open access research for "The DS Biomarker 
Initiative (DSBI)". Frontiers in Behavioural Neuroscience. Published online September 14, doi: 10.3389/fnbeh.2015.00239 (2015)

[11] S. Stengel-Rutkowski. Neuropadietrie; Aksu, Fuat2. Auflage-Bremen: UNI-MED, 2004 (UNI-MED SCIENCE); 135-137

[12] Dzemdību un dzimušo skaits - http://data.csb.gov.lv/pxweb/lv

[13] W. Horner-Johnson, C.E. Drum. Ment. Retard. Dev. Disabil. Res. Rev. 12, 57-69 (2006)

[14] L.J. Brooks, M.N. Olsen, A.M. Bacevice, A. Beebe, S. Konstantinopoulou, H.G. Taylor, Sleep Breath. 19, 197-204 (2015). 10.1007/s11325-014-0992-y

[15] Better Care Network Working Paper September 2010; John Williamson and Aaron Greenberg; http://www.crin.org/en/docs/Families\%20Not\%200rphanages. pdf; cited 2017/20/08; 5-10

[16] K. Browne, The Risk of Harm to Young Children in Institutional Care (Published by Save the Children 1 St John's Lane, London, 2009), pp. 6-16

[17] A. Mohammed Nawi, A. Ismail, S. Abdullah, Iran J. Pub. Health. 42(9), 996-1006 (2013) Sep; ID: PMC4453896

[18] C. DiGuiseppi, S. Hepburn, J.M. Davis, D.J. Fidler, S. Hartway, N.R. Lee, L. Miller, M. Ruttenber, C. Robinson J. Dev. Behav. Pediatr. 31(3), 181-91 (2010) doi: 10.1097/DBP.0b013e3181d5aa6d 